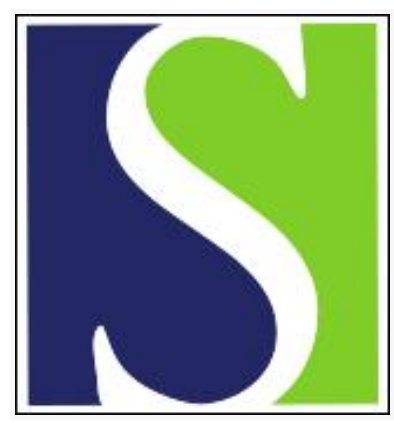

Scand J Work Environ Health 2015;41(3):288-293

https://doi.org/10.5271/sjweh.3486

Published online: 20 Feb 2015, Issue date: 01 May 2015

Enhanced preference for high-fat foods following a simulated night shift

by Cain SW, Filtness AJ, Phillips CL, Anderson C

Shortened sleep and circadian misalignment, as seen in shift workers, has adverse metabolic and behavioral consequences which lead to obesity and associated comorbidities. This study demonstrates a simulated night shift enhances preference for high fat foods, which may be a contributing factor for shift work-related weight gain. Increasing awareness of changes in food preference may promote healthier food choices.

Affiliation: School of Psychological Sciences, Monash University, Clayton, VIC, 3800, Australia. clare.anderson@monash.edu

Refers to the following texts of the Journal: 2005;31(1):30-35 2009;35(3):163-179 2010;36(2):150-162

The following articles refer to this text: 2020;46(5):533-541; 2020;46(6):579-588

Key terms: diet; dietary intake; eating; fat; food; habit; health; health; high-fat food; night duty; night shift; night work; nutrition; obesity; shift work; shift worker; simulated night shift; sleep loss; weight gain

This article in PubMed: www.ncbi.nlm.nih.gov/pubmed/25699635 


\title{
Enhanced preference for high-fat foods following a simulated night shift
}

\author{
by Sean W Cain, PhD, ${ }^{1}$ Ashleigh J Filtness, PhD, ${ }^{2}$ Craig L Phillips, PhD, ${ }^{3,4}$ Clare Anderson, PhD 1,5
}

\begin{abstract}
Cain SW, Filtness AJ, Phillips CL, Anderson C. Enhanced preference for high-fat foods following a simulated night shift. Scand J Work Environ Health. 2015;41(3):288-293. doi:10.5271/sjweh.3486

Objectives Shift workers are prone to obesity and associated co-morbidities such as diabetes and cardiovascular disease. Sleep restriction associated with shift work results in dramatic endocrine and metabolic effects that predispose shift workers to these adverse health consequences. While sleep restriction has been associated with increased caloric intake, food preference may also play a key role in weight gain associated with shift work. This study examined the impact of an overnight simulated night shift on food preference.
\end{abstract}

Methods Sixteen participants [mean 20.1, standard deviation (SD) 1.4 years; 8 women] underwent a simulated night shift and control condition in a counterbalanced order. On the following morning, participants were provided an opportunity for breakfast that included high- and low-fat food options (mean $64.8 \%$ and $6.4 \%$ fat, respectively).

Results Participants ate significantly more high-fat breakfast items after the simulated night shift than after the control condition [167.3, standard error of the mean (SEM) 28.7) g versus 211.4 (SEM 35.6) g; $\mathrm{P}=0.012$ ]. The preference for high-fat food was apparent among the majority of individuals following the simulated night shift (81\%), but not for the control condition (43\%). Shift work and control conditions did not differ, however, in the total amount of food or calories consumed.

Conclusions A simulated night shift leads to preference for high-fat food during a subsequent breakfast opportunity. These results suggest that food choice may contribute to weight-related chronic health problems commonly seen among night shift workers.

Key terms diet; dietary intake; eating; food; habit; health; night duty; night work; nutrition; obesity; shift work; shift worker; sleep loss; weight gain.

Working shifts outside of regular working hours is prevalent in modern industrialized work places $(1,2)$. While the immediate risk for shift workers includes heightened fatigue, disturbed sleep, and increased accident risk (3, 4), prolonged shift work has also been associated with long-term adverse health issues. Shift workers are prone to obesity (5-9) and associated co-morbidities such as diabetes $(5,6,8)$, high cholesterol $(7-10)$, cardiovascular disease $(5,6,11,12)$, gastrointestinal problems $(5,6,13)$, and metabolic disturbances $(5,6,14-16)$. In addition, shift workers have an increased risk for coronary heart disease and stroke with mortality rates being highest among workers with the longest history of shift work (17-20).
Both sleep restriction and circadian misalignment contribute to the dysmetabolism of shift workers. Insufficient sleep is associated with a higher probability of becoming obese (21), which may be due, in part, to a reduction in serum leptin (an appetite inhibitor), and increase in serum ghrelin (a hunger stimulator) (13, 22). Further, shortened sleep leads to insulin resistance and an impaired clearance of glucose following food intake (23). In addition to sleep restriction, circadian disruption also occurs among shift workers, as the timing of sleep and wake becomes desynchronized with the internal circadian clock. Laboratory studies with highly-controlled food intake have demonstrated that when sleep and wake cycles are misaligned with the

1 School of Psychological Sciences, Monash University, Clayton, VIC, Australia.

2 Centre for Accident Research and Road Safety - Queensland (CARRS-Q), Queensland University of Technology, QLD, Australia.

3 Woolcock Institute of Medical Research, University of Sydney, Camperdown, NSW Australia.

4 Royal North Shore Hospital, St Leonards NSW, Australia.

5 Sleep Research Centre, Loughborough University, Leicestershire, UK.

Correspondence to: Clare Anderson, School of Psychological Sciences, Monash University, Clayton, VIC, 3800, Australia. [E-mail: clare. anderson@monash.edu] 
underlying circadian rhythm, circulating leptin levels are significantly lower than when they are aligned (24), even without accompanying sleep restriction. Thus, with a decreased satiety signal, the night shift worker is likely to consume more food. While both sleep restriction and circadian misalignment have been independently shown to affect appetite and metabolism, the most profound effects are seen when these are combined, as is typically seen in shift work. Chronic sleep restriction and circadian misalignment results in significantly decreased resting metabolic rate and an inadequate pancreatic insulin secretion, leading to increased post-meal glucose concentrations (25). The physiological effect of sleep restriction and circadian misalignment among shift workers therefore promotes both overeating and a decreased ability of the body to use the energy consumed, thus predisposing individuals to metabolic disease.

In support of these observations, working through the night has been associated with an increase in consuming snacks (16). Field-based studies have reported that shift workers consume more calories (26) and more saturated fats (27), often due to workers opting for snack options that are convenient and easy to obtain (28). However, studies evaluating the impact of shift work or shortened sleep on food preference have utilized self-reporting techniques, such as food diaries, questionnaires or interviews [eg, (5)]. While informative of food intake among shift workers, these techniques convey little information about food choice or macro-nutrient preference when a variety of options are actually available. Despite this, the outcomes are corroborated by well-controlled laboratorybased studies. For instance, artificial sleep restriction has been associated with increased self-reported hunger and appetite, more specifically for carbohydrates (22, $29)$ and increased propensity for consuming snacks (30, 31 ), particularly sweet snacks (31). While preference for carbohydrate increases with shortened sleep, the self-reported preference for protein remains unchanged $(22,28)$. Despite excess dietary fat being a risk factor for obesity, the effect of night shift work on the preference for dietary fat remains unclear, with some studies demonstrating an effect of sleep curtailment on dietary fat intake $(32,33)$ and some showing no change $(28)$. While data exists with respect to snacking and eating on shift, no study has examined the impact of night shift work on food preference post-shift. To address this, we investigated the preference for low- or high-fat 'breakfast' foods consumed after a simulated night shift compared to a control condition among the same individuals. We hypothesized that the simulated night shift would result in a greater preference for higher-fat food choices.

\section{Methods}

\section{Participants}

Sixteen adults [mean 20.1, standard deviation (SD) 1.4 years; 8 women] were studied. Participants were free from psychiatric or major medical problems, medications affecting the central nervous system and had normal body mass indices (BMI) (20-25). Participants took $<2$ daytime naps per week and/or had normal daytime sleepiness scores $[<10$ on the Epworth Sleepiness Scale (34); mean 5.2 (SD 2.9)] and slept 7-9 hours/night. Participants who were current or past night shift workers, or who reported extreme morning or evening chronotype, were excluded from the study. Informed consent was provided. Loughborough University Ethics Committee approved the study.

\section{Study overview}

Participants attended the laboratory on two occasions (control and simulated night shift) after week-long screening to ensure consistent sleep/wake schedules. Control and simulated shift conditions were counter-balanced. On one occasion, participants slept at home, monitored by actigraphy [7.39 (SD 0.34) hours; range 7.08-8.53 hours]. At 08:00 hours, participants arrived at the laboratory and were provided with breakfast before undertaking a series of neurocognitive tests [as part of another study (34)]. On a separate occasion, separated by $\geq 1$ week, participants slept at home, monitored by actigraphy [7.40, (SD 0.18) hours; range 7.10-8.30 hours], woke at 08:00 hours and continued their normal activities before arriving at the laboratory at 20:00 hours. Participants were kept awake overnight to simulate a night shift. During the night, participants completed neurocognitive test batteries and interacted as part of a group, simulating a typical night shift work environment. To minimize increased hunger before breakfast, participants on the night shift had ad libitum access to food served between 0:00-03:00 hours. The food preferences were examined in a breakfast buffet provided at 08:00 hours for the control and simulated night shift conditions. Available food was identical on each occasion.

\section{Measurements}

After normal sleep and a simulated night shift, a choice of breakfast foods were presented as a buffet. Food items were classified into two fat contents: high or low fat (see table 1). Participants ate alone during a 15-minute window of opportunity. Participants were told to eat as much or as little as they desired and were unaware that their food consumption was being quantified. The amount of each food item eaten was calculated. 
Table 1. Serving size and micronutrient content of food items presented as part of the breakfast buffet. Serving sizes were 2.5 times the standard serve to allow for over-eating.

\begin{tabular}{lcrrr}
\hline Breakfast item & $\begin{array}{c}\text { Serving size } \\
\text { (grams) }\end{array}$ & \multicolumn{3}{c}{ Nutritional ratio (\%) } \\
\cline { 3 - 5 } & & Carbohydrate & Fat & Protein \\
\hline High-fat food choices & & & & \\
Peanut butter & 80 & 15 & 71 & 14 \\
Butter & 35 & 0 & 99 & 1 \\
Boiled egg & 125 & 3 & 62 & 35 \\
Greek yoghurt & 312.5 & 12 & 54 & 34 \\
High fat soft cheese & 37.5 & 5 & 88 & 7 \\
Cheddar cheese & 75 & 2 & 72 & 26 \\
Chocolate biscuits & 70 & 53 & 42 & 5 \\
Nutella & 92.5 & 47 & 49 & 4 \\
Croissant & 142.5 & 46 & 46 & 8 \\
Average & & 20.3 & 64.8 & 14.9 \\
Low-fat food choices & & & & \\
White bread & 2.5 a & 78 & 11 & 11 \\
Ham & 67.5 & 3 & 22 & 75 \\
Marmite & 10 & 0 & 0 & 100 \\
Light soft cheese & 37.5 & 28 & 8 & 64 \\
Fruit salad (mandarin/ & 290 & 92 & 4 & 4 \\
grapes/banana) & & & & \\
Strawberry jam & 50 & 99 & 0 & 1 \\
Honey & 50 & 100 & 0 & 0 \\
Average & & 57.2 & 6.4 & 36.4 \\
\hline a Slices & & & &
\end{tabular}

a Slices

\section{Statistical analysis}

Total amount of food consumed (g) was calculated for each participant, per condition, and compared using paired sample t-tests. The total amount of food consumed was calculated for high- and low-fat foods for each condition. These were compared using a two-way repeated measure analysis of variance (ANOVA) for SHIFT (control versus simulated shift) and FAT (high versus low). Total amount of protein (g), carbohydrate (g), and calorie content was calculated. Normality of data was confirmed using Shapiro-Wilk tests. Mean and standard error of the mean (SEM) are reported unless otherwise stated.

\section{Results}

A paired sample t-test revealed no significant difference $(\mathrm{P}=0.73)$ in the total weight of food consumed for breakfast after the control night [389.9 (SEM 29.1) g], compared to the simulated night shift [377.0 (SEM 34.3) g]. A two-way repeated measures ANOVA examining SHIFT (control versus night shift) and FAT (high versus low fat) revealed a significant interaction between SHIFT and FAT, such that participants ate more high-fat foods after the simulated night shift $[167.3$ (SEM 28.7) $\mathrm{g}$ versus 211.4 (SEM 35.6) g, $\mathrm{F}=8.127$, df. 1,15, $\mathrm{P}=0.012$, $\left.\eta^{2}=0.35\right]$. There were no significant main effects of
SHIFT $(\mathrm{P}=0.73)$ or FAT $(\mathrm{P}=0.85)$. See figure 1 .

Following the simulated night shift, the total food consumption increased for only $5 / 16$ participants $(31.25 \%)$, however, the majority of individuals $(13 / 16 ; 81.25 \%)$ ate more of the high-fat food options after the simulated night shift compared to the control condition $(7 / 16 ; 43.75 \%)$.

There was no significant differences in the amount of carbohydrate [220.8 (SEM 26.5) g versus 182.9 (SEM 32.9) g, $\mathrm{P}=0.187]$, protein [61.4 (SEM 10.1) g versus 66.3 (SEM 10.4) g, $\mathrm{P}=0.445$ ] or calories [795.8 (SEM 127.9) calories versus 733.0 (SEM 0.95) calories, $\mathrm{P}=0.35]$ consumed after the simulated night shift compared to the control condition.

\section{Discussion}

Our findings demonstrate that sleep restriction during a simulated night shift increases preference for highfat foods among the same individuals. Participants undergoing a simulated night shift (constituting one night without sleep) demonstrated an increased preference for high-fat breakfast food compared to their own preferences when well-rested. This effect was striking, with $81 \%$ of participants choosing high-fat foods after the simulated night shift.

The preference for food with a higher calorie content (higher carbohydrate and fat over higher protein foods) following sleep restriction has been supported by several studies $(30,31,35)$. In our study, although higher fat foods were chosen after a simulated night shift, overall calories consumed and amount of food did not differ. Our finding of "no increase in calories consumed" likely reflects the limited time available for eating the breakfast. In our study, participants had only 15 minutes to eat which is a potential methodological limitation. Had the time to eat been unrestricted, differences in the caloric content and amount of food may have been seen. In the absence of an increase in energy expenditure, any increase in caloric intake would result in weight gain. In this context, a recent study has shown that a simulated nightshift decreases total daily energy expenditure when caloric intake is fixed (36). This, alongside our data, suggests that shift workers who have ad-libitum access to food will be especially prone to weight gain.

Though our study was designed to simulate a first night effect of night shift on food choices at breakfast, it does not address whether similar eating patterns would persist at subsequent meals when intervening daytime sleep periods usually occur. It is possible that healthier food choices may manifest as the acute effects of sleep deprivation subside during subsequent night shifts. Longer-term study under naturalistic settings would be necessary to determine if the choice of higher fat 


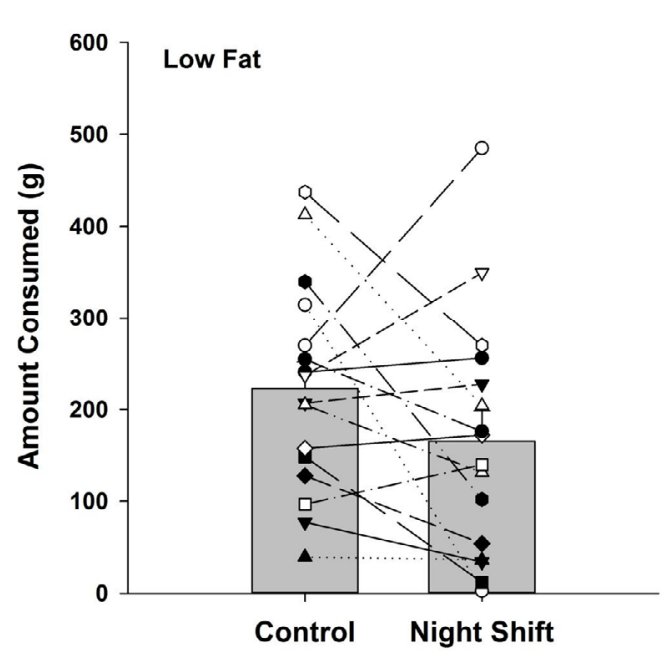

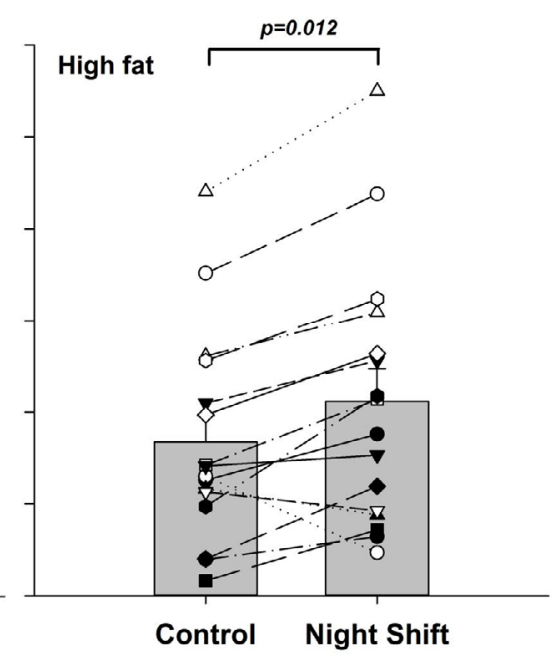

Figure 1. Average amount of high- and low-fat food consumed across conditions (control versus night shift). Lines represent individual changes in preference for high and low fat foods across the two conditions. food would persist. In addition, because our participant sample were young individuals without experience of night shift work, further work should establish whether these findings remain for individuals who are more representative of shift worker populations.

It has been proposed that readily available unhealthy foods such as fast food in vending machines promotes poor nutritional habits amongst shift workers (28). Whilst some field studies of shift workers diets do suggest that their dietary patterns are altered, the studies are few and the findings are not consistent. In a recent systematic review of obesity and nutritional patterns amongst shift workers, Amani et al (37) found that one of two cross-sectional studies suggested higher food intake among shift workers. In addition, two of four cohort studies showed a higher number of meals and/ or lower nutritional quality among shift workers. These inconsistent findings may be related to very low sample sizes and/or poor methods for measuring macronutrient intake. Overall, they highlight the great need for larger studies that employ more reliable methods to assess dietary habits and the impact on obesity and other health outcomes. Nevertheless, from a mechanistic perspective, the present findings suggest that sleep restriction and circadian misalignment during night shift work itself may enhance the preference for such unhealthy foods. The increased appetite and decreased satiety signals that result from sleep restriction and circadian misalignment seen in shift work may lead to preferences for high fat foods. An increased intake of such foods, coupled with weight gain-promoting dysmetabolism (eg, insulin insufficiency, increased post-prandial glucose, and decreased resting metabolic rate) creates a constellation of physiological events that promote weight gain and associated co-morbidities such as diabetes and cardio- vascular disease among night shift workers. Our findings suggest that promoting the awareness of the effects of shift work on poor food choices may improve the health of shift workers through prevention of weight gain and associated metabolic consequences.

\section{Acknowledgments}

The authors would like to thank Holly Penalver for overseeing and administering the breakfast to all participants, including measuring all food portions; Garry Woodward, May Farskoury, and Hannah Del Manso for recruitment and research assistance; and Dr Charlotte Platten for overseeing the simulated night shift.

\section{Financial declaration}

The authors have no financial or other relationships which represent a conflict of interest for the work as described in this manuscript. In the interest of full disclosure, Dr Clare Anderson reports receiving a research award/prize from Sanofi-Aventis and lecturing fees from Brown Medical School/Rhode Island Hospital, Ausmed Australia and Rio Tinto. She has also received contract research funding from Pacific Brands and VicRoads through an agreement with Monash University. She has served as consultant to the Rail, Bus and Tram Union, the National Transport Commission, the Transport Accident Commission, and VicPolice. She is a participant in the Cooperative Research Centre for Alertness, Safety and Productivity. SWC acknowledges contract research funding from Pacific Brands through an agreement with Monash University. 


\section{References}

1. Australian Bureau of Statistics. Working time arrangements, 2009: Canberra, Australia.

2. Gordon NP, Cleary PD, Parker CE, Czeisler CA. The prevalence and health impact of shiftwork. Am J Public Health. 1986; 76(10):1225-1228. http://dx.doi.org/10.2105/ AJPH.76.10.1225

3. Folkard S,Tucker P. Shift work, safety and productivity. Occup Med. 2003; 53(2):95-101. http://dx.doi.org/10.1093/occmed/ kqg047

4. Rajaratnam SM, Arendt J. Health in a 24-h society. Lancet. 2001;358(9286):999-1005. http://dx.doi.org/10.1016/S01406736(01)06108-6

5. Lowden A, Moreno C, Holmbäck U, Lennernäs M, Tucker P. Eating and shift work- effects on habits, metabolism, and performance. Scand J Work Environ Health. 2010;36(2):150162. http://dx.doi.org/10.5271/sjweh.2898

6. Pine B, St Amand B, Katz J. Shift Work and Sleep. J Occup Environ Med. 2011;53(5 Suppl):S1-102011.

7. Karlsson BH, Knutsson AK, Lindahl BO, Alfredsson LS. Metabolic disturbances in male workers with rotating three-shift work. Results of the WOLF study. Int Arch Occup Environ Health. 2003;76(6):424-430. http://dx.doi. org/10.1007/s00420-003-0440-y

8. Karlsson B, Knutsson A, Lindahl B. Is there an association between shift work and having a metabolic syndrome? Results from a population based study of 27 485 people. Occup Environ Med. 2001;58(11):747-752. http://dx.doi.org/10.1136/oem.58.11.747

9. Nakamura K, Shimai S, Kikuchi S, Tominaga K, Takahashi $\mathrm{H}$, Tanaka M, et al. Shift work and risk factors for coronary heart disease in Japanese blue-collar workers: serum lipids and anthropometric characteristics. Occup Med (Lond). 1997;47(3):142-146. http://dx.doi.org/10.1093/ occmed/47.3.142

10. Ghiasvand M1, Heshmat R, Golpira R, Haghpanah V, Soleimani A, Shoushtarizadeh P, Tavangar SM, Larijani B. Shift working and risk of lipid disorders: a cross-sectional study. Lipids Health Dis. 2006;5(1):9. http://dx.doi. org/10.1186/1476-511X-5-9

11. Frost P, Kolstad HA, Bonde JP. Shift work and the risk of ischemic heart disease-a systematic review of the epidemiologic evidence. Scand J Work Environ Health. 2009;35(3):163-79. http://dx.doi.org/10.5271/sjweh.1319

12. Kawachi I, Colditz GA, Stampfer MJ, Willett WC, Manson JAE, Speizer FE, et al. Prospective study of shift work and risk of coronary heart disease in women. Circulation. 1995;92(11):3178-3182. http://dx.doi.org/10.1161/01. CIR.92.11.3178

13. Costa G. The impact of shift and night work on health. Appl Ergon. 1996;27(1):9-16. http://dx.doi.org/10.1016/00036870(95)00047-X

14. Crispim CA, Zalcman I, Dáttilo M, Padilha HG, Edwards B,
Waterhouse J, et al. The influence of sleep and sleep loss upon food intake and metabolism. Nutr Res Rev. 2007;20(2):195212. http://dx.doi.org/10.1017/S0954422407810651

15. Esquirol Y, Bongard V, Mabile L, Jonnier B, Soulat JM, Perret B. Shift work and metabolic syndrome: respective impacts of job strain, physical activity, and dietary rhythms. Chronobiol Int. 2009;26(3):544-59. http://dx.doi. org/10.1080/07420520902821176

16. Biggi N, Consonni D, Galluzzo V, Sogliani M, Costa G. Metabolic syndrome in permanent night workers. Chronobiol Int. 2008;25(2):443-54. http://dx.doi. org/10.1080/07420520802114193

17. Brown DL, Feskanich D, Sánchez BN, Rexrode KM, Schernhammer ES, Lisabeth LD. Rotating night shift work and the risk of ischemic stroke. Am J Epidemiol. 2009;169(11):1370-7. http://dx.doi.org/10.1093/aje/ kwp056

18. Karlsson B, Alfredsson L, Knutsson A, Andersson E, Torén K. Total mortality and cause-specific mortality of Swedish shiftand dayworkers in the pulp and paper industry in 1952-2001. Scand J Work Environ Health. 2005;31(1):30-5. http://dx.doi. org/10.5271/sjweh.845

19. Vyas MV, Garg AX, Iansavichus AV, Costella J, Donner A, Laugsand LE, et al. Shift work and vascular events: systematic review and meta-analysis. BMJ. 2012;345:e4800. http:// dx.doi.org/10.1136/bmj.e4800

20. Esquirol Y, Bongard V, Mabile L, Jonnier B, Soulat JM, Perret B. Shift work and metabolic syndrome: respective impacts of job strain, physical activity, and dietary rhythms. Chronobiol Int. 2009;26(3):544-59. http://dx.doi. org/10.1080/07420520902821176

21. Spiegel K, Tasali E, Penev P, Van Cauter E. Brief communication: sleep curtailment in healthy young men is associated with decreased leptin levels, elevated ghrelin levels, and increased hunger and appetite. Ann Intern Med. 2004; 7;141(11):846-50.

22. Spiegel K, Leproult R, Van Cauter E. Impact of sleep debt on metabolic and endocrine function. Lancet, 1999. 354(9188):1435-9. http://dx.doi.org/10.1016/S01406736(99)01376-8

23. Scheer FA, Hilton MF, Mantzoros CS, Shea SA. Adverse metabolic and cardiovascular consequences of circadian misalignment. Proc Natl Acad Sci U S A. 2009;106(11):44538. http://dx.doi.org/10.1073/pnas.0808180106

24. Buxton OM, Cain SW, O'Connor SP, Porter JH, Duffy JF, Wang W, Czeisler CA, Shea SA. et al. Adverse metabolic consequences in humans of prolonged sleep restriction combined with circadian disruption. Sci Transl Med. 2012;4(129):129ra43.

25. Geliebter A, Gluck ME, Tanowitz M, Aronoff NJ, Zammit GK. Work-shift period and weight change. Nutrition. 2000;16(1):27-29. http://dx.doi.org/10.1016/S08999007(99)00228-2

26. Di Lorenzo L, De Pergola G, Zocchetti C, L'Abbate N, Basso A, Pannacciulli N, et al. Effect of shift work on body mass 
index: results of a study performed in 319 glucose-tolerant men working in a Southern Italian industry. Int J Obes Relat Metab Disord. 2003;27(11):1353-8. http://dx.doi.org/10.1038/ sj.ijo.0802419

27. de Assis MA, Kupek E, Nahas MV, Bellisle F. Food intake and circadian rhythms in shift workers with a high workload. Appetite. 2003;40(2):175-83. http://dx.doi.org/10.1016/ S0195-6663(02)00133-2

28. Benedict C, Brooks SJ, O'Daly OG, Almèn MS, Morell A, Åberg K, et al. Acute Sleep Deprivation Enhances the Brain's Response to Hedonic Food Stimuli: An fMRI Study J Clin Endocrinol Metab. 2012;97(3):E443-7. http://dx.doi. org/10.1210/jc.2011-2759

29. Nedeltcheva AV, Kilkus JM, Imperial J, Kasza K, Schoeller DA, Penev PD. Sleep curtailment is accompanied by increased intake of calories from snacks. Am J Clin Nutr. 2009;89(1):12633. http://dx.doi.org/10.3945/ajcn.2008.26574

30. Heath G, Roach GD, Dorrian J, Ferguson SA, Darwent $\mathrm{D}$, Sargent C. The effect of sleep restriction on snacking behaviour during a week of simulated shiftwork. Accid Anal Prev. 2012;45 Suppl:62-7. http://dx.doi.org/10.1016/j. aap.2011.09.028

31. Schmid SM1, Hallschmid M, Jauch-Chara K, Wilms B, Benedict C, Lehnert H, et al., Short-term sleep loss decreases physical activity under free-living conditions but does not increase food intake under time-deprived laboratory conditions in healthy men. Am J Clin Nutr. 2009;90(6):1476-82. http:// dx.doi.org/10.3945/ajen.2009.27984

32. Brondel L, Romer MA, Nougues PM, Touyarou P, Davenne D. Acute partial sleep deprivation increases food intake in healthy men. Am J Clin Nutr. 2010;91(6):1550-9. http://dx.doi. org/10.3945/ajen.2009.28523

33. Anderson C, Platten CR. Sleep deprivation lowers inhibition and enhances impulsivity to negative stimuli. Behav Brain Res. 2011;217(2):463-6. http://dx.doi.org/10.1016/j. bbr.2010.09.020

34. McHill AW, Melanson EL, Higgins J, Connick E, Moehlman TM, Stothard ER et al. Impact of circadian misalignment on energy metabolism during simulated nightshift work. Proc Natl Acad Sci U S A. 2014;111(48):17302-7. http://dx.doi. org/10.1073/pnas.1412021111

35. Amani R, Gill T. Shiftworking, nutrition and obesity: implications for workforce health- a systematic review. Asia Pac J Clin Nutr. 2013;22(4):505-15.

Received for publication: 15 September 2014 